УДК $581.524 .4(470.0)$

СООБЩЕСТВА КЛАССОВ PAPAVERETEA RHOEADIS S. BRULLO ET AL. 2001 И SISYMBRIETEA GUTTE ET HILBIG 1975 В ЮЖНОМ НЕЧЕРНОЗЕМЬЕ РОССИИ

\begin{abstract}
А.Д. Булохов, И.М. Ивенкова, Н.Н. Панасенко
Брянский государственный университет им. акад. И. Г. Петровского, Брянск

Приведены результаты классификации антропогенной растительности Южного Нечерноземья России, представляющей классы Papaveretea rhoeadis и Sisymbrietea. Установлено 5 новых ассоциации сегетальной и рудеральной растительности: Apero spicae-venti-Elytrigetum repentis, Convolvulo arvensi-Erigeronetum canadensis, Chenopodio albi-Setarietum pumilae, Artemisio vulgaris-Tripleurospermetum inodori, Atriplici patulaeTripleurospermetum inodori. Сообщества ассоциаций представляют быстро проходящие стадии восстановительной сукцессии на залежах. Ассоциации включены в состав союзов: Galeopsion bifidae, Oxalidion europaeae, Scleranthion annui, Atriplicion.

Ключевые слова: классификация, метод Браун-Бланке, антропогенная растительность, сегетальные и рудеральные сообщества, Papaveretea rhoeadis, Sisymbrietea, Брянская область.
\end{abstract}

DOI: $10.26456 /$ vtbio 75

Введение. Антропогенная растительность получила широкое распространение в связи с интенсивной деятельностью человека. В составе этой растительности выделяют сегетальную (сорно-полевые растительные сообщества в агроценозах) и рудеральную (растительные сообщества, сформированные в транспортных, промышленных, строительных, селитебных местообитаниях).

По классификации антропогенной (синантропной) растительности региона имеется ряд публикаций, посвященных классам Artemisietea vulgaris Lohmeyer et al. in Tx. ex von Rochow 1951 (Булохов, Харин, 2008; Булохов, Ивенкова, 2013; Булохов и др., 2016; Панасенко и др., 2012, 2013; Поцепай, 2008) и Digitario sanguinalisEragrostietea minoris Mucina, Lososova et Silc 2016 (Булохов, 2017). В этих работах встречаются фрагментарные материалы о сегетальной растительности.

Цель работы - выявить разнообразие сегетальной и рудеральной растительности в Южном Нечерноземье России в границах Брянской области и разработать синтаксономию классов Papaveretea rhoeadis и Sisymbrietea, представленных в регионе. 
Методика. Изучение антропогенной растительности проведено детально-маршрутным методом. В течение полевых сезонов 20002017 гг. выполнено более 150 полных геоботанических описаний на пробных площадях 25-100 $\mathrm{m}^{2}$. Для разработки флористической классификации на основе метода Ж. Браун-Бланке (Braun-Blanquet, 1964) использовано 102 описания.

Оценка количественного участия видов дана по комбинированной шкале Ж. Браун-Бланке (Braun-Blanquet, 1964): «r»очень редки, 1-4 особи; «+»- разрежены и покрывают менее $1 \%$ площадки; «1» - особи многочисленны, но покрывают не более 5\% площадки или довольно разрежены, но с такой, же величиной покрытия; «2» - от 6 до 25\%; «3» - от 26 до 50\%; «4»- от 50 до 75\%; «5» - более 75\%. Классы постоянства (Кп) в таблицах даны римскими цифрами по пятибалльной шкале: I - вид присутствует, менее чем в $20 \%$ описаний, II - 21-40\%, III - 41-60\%, IV - 61-80\%, V - в более $80 \%$ описаний. Если число описаний синтаксона меньше 6, то Кп приводится арабскими цифрами.

Названия новых синтаксонов, их диагноз приведены в соответствии с Международным кодексом фитосоциологической номенклатуры (Weber et al., 2000). Номенклатура синтаксонов высших рангов дана по Mucina L. et al. (2016). Характерные виды ассоциаций при сравнении фитоценонов установлены по двум критериям: класс постоянства и обилие-покрытие. Дана оценка синтаксономического положения установленных ассоциаций и ранее описанными синтаксонами для Европы зарубежными и отечественными фитоценологами.

Синэкологические оптимумы синтаксонов по влажности, кислотности и обеспеченности минеральным азотом почвы определены по экологическим шкалам Х. Элленберга (Ellenberg et al., 1992) с использованием программы Indicator для MS Excel (Булохов, Семенищенков, 2006). Номенклатура латинских названий растений приведена по сводке П. Ф. Маевского (2014).

Результаты и обсуждение. Итогом выполненной классификации стал продромус сегетальной и рудеральной растительности Южного Нечерноземья России и экологофлористическая характеристика установленных синтаксонов.

\section{Продромус}

Класс Papaveretea rhoeadis S. Brullo et al. 2001

Порядок Aperetalia spicae-venti J. Tx. et Tx. in Malato-Beliz et al. 1960 Союз Scleranthion annui (Kruseman et Vlieger 1939) Sissingh in

Westhoff et al. 1946

Acc. Apero spicae-venti-Elytrigetum repentis ass. nov. hoc loco

Союз Galeopsion bifidae Abramova in Mirkin et al. 1985

Acc. Convolvulo arvensi-Erigeronetum canadensis ass. nov. hoc loco 
Acc. Chenopodio albi-Setarietum pumilae ass. nov. hoc loco

Субасс. Ch.a-S.p. typicum subass. nov. hoc loco

Субасc. Ch.a- S.p. lepidietosum densifloris subass. nov. hoc loco

Acc. Setario pumilae-Galinsogetum parviflorae Tx. $1950 \mathrm{em}$.

Th.Müller et Oberdorfer in Oberdorfer 1983

Союз Oxalidion fontanae Passarge 1978

Acc. Artemisio vulgaris-Tripleurospermetum inodori ass. hoc. hoc loco

Варинаты: Arabidopsis thaliana, typica

Класс Sisymbrietea Gutte et Hilbig 1975

Порядок Sisymbrietalia sophiae J. Tx. ex Görs 1966

Союз Atriplicion Passarge 1978

Acc. Sisymbrietum loeselii (Krech 1935) Gutte 1972

Сообщество Sisymbrium volgense [Sisymbrietalia sophiae]

Acc. Atriplici patulae-Tripleurospermetum inodori ass. nov. hoc loco

Acc. Ivaetum xanthiifoliae Fijałkowski 1967

Субасc. Ivaetum xanthiifoliae arctietosum tomentosi subass. nov. hoc loco

Класс Papaveretea rhoeadis S. Brullo et al. 2001

Объединяет сегетальную растительность, сформированную однолетниками в полевых (зерновых) и пропашных культурах, залежах, садах. Сообщества класса представляют начальные стадии восстановительной сукцессии. В составе класса один порядок Aperetalia spicae-venti J.Tx. et Tx. in Malato-Beliz et al. 1960. В составе порядка установлено 3 союза: Scleranthion annui (Kruseman et Vlieger 1939) Sissingh in Westhoff et al. 1946 (сообщества полевых культур на супесчаных и супесчано-суглинистых почвах); Oxalidion europaeae Passarge 1978 (сообщества полевых и пропашных культур, огородов и залежей); Galeopsion bifidae Abramova in Mirkin et al. 1985 (сообщества, сформированные однолетниками в полевых и пропашных культурах, залежах, садах на кислых песчано-глинистых почвах в неморальной, гемибореальной и арктической зонах Восточной Европы и Сибири).

Состав характерных видов этих союзов имеет много общих видов, и не всегда удается провести четкие границы между группам этих видов, так как сообщества союзов представляют быстро проходящие стадии восстановительной сукцессии, существуют непродолжительное время, сменяясь при отсутствии нарушений на достаточно устойчивые и флористически разнообразные сообщества.

Ассоциация Apero spicae-venti-Elytrigetum repentis ass. nov. hoc loco (табл. 1; номенклатурный тип (holotypus) - оп. 1).

Характерные виды (X. в.): Apera spica-venti, Centaurea cyanus, Elytrigia repens, Vicia tetrasperma. 
Таблица 1

Ассоциация Apero spicae-venti-Elytrigetum repentis ass. nov. hoc loco

\begin{tabular}{|c|c|c|c|c|c|c|c|c|c|c|c|c|c|c|c|c|c|}
\hline Номера описаний & 1 & 2 & 3 & 4 & 5 & 6 & 7 & 8 & 9 & 10 & 11 & 12 & 13 & & 15 & 16 & Кп \\
\hline ОПП, \% & 40 & 40 & 60 & 60 & 60 & 60 & 50 & 60 & 95 & 90 & 80 & 60 & 50 & 60 & 80 & 80 & \\
\hline идов & 20 & 16 & 17 & 20 & 15 & 13 & 20 & 16 & 19 & 18 & 16 & 10 & 18 & 16 & 11 & 19 & \\
\hline \multicolumn{18}{|c|}{ Х. в. асс. Apero spicae-venti-Elytrigetum rpentis } \\
\hline Apera spica-venti & 3 & 2 & 2 & 2 & 2 & 1 & 1 & 2 & + & 2 & 2 & 3 & 2 & 2 & 3 & 1 & $\mathrm{~V}$ \\
\hline Elytrigia repens & 2 & 1 & 3 & . & 2 & 3 & 4 & 4 & 4 & + & + & . & 4 & 4 & . & 2 & $\mathrm{~V}$ \\
\hline Centaurea cyanus & 1 & 1 & + & + & + & + & $\mathrm{r}$ & + & + & . & $\mathrm{r}$ & . & $\mathrm{r}$ & + & 1 & 1 & $\mathrm{~V}$ \\
\hline Vicia tetrasperma & + & + & + & . & + & + & + & + & & + & + & + & + & + & . & . & IV \\
\hline \multicolumn{18}{|c|}{ Х. в. союза Sclerantion annnui и порядка Aperetalia spicae-venti } \\
\hline Setaria pumila & + & . & 1 & . & + & 1 & . & . & . & + & + & . & . & . & . & . & II \\
\hline Galeopsis bifida & . & . & $\mathrm{r}$ & . & . & . & $\mathrm{r}$ & . & + & . & . & . & . & . & . & . & II \\
\hline Bromus secalinus & . & . & + & . & + & + & . & + & . & . & . & . & . & + & . & . & II \\
\hline Linaria vulgaris & . & . & . & . & . & . & $\mathrm{r}$ & . & $\mathrm{r}$ & . & . & . & $\mathrm{r}$ & . & . & . & I \\
\hline Viola & . & . & . & + & + & . & . & . & . & . & . & . & . & + & . & $\mathrm{r}$ & I \\
\hline \multicolumn{18}{|c|}{ Х.в. класса Papaveretea rhoeadis } \\
\hline nadensis & + & . & . & + & + & + & + & + & 1 & 1 & 2 & + & + & + & + & + & $\mathrm{V}$ \\
\hline Tripleurospermum inodorum & + & . & + & + & + & + & . & + & + & + & + & . & + & + & $\mathrm{r}$ & 3 & IV \\
\hline Sonchus arvensis & + & + & 1 & $\mathrm{r}$ & . & 1 & 1 & + & . & . & . & + & 2 & . & . & $\mathrm{r}$ & III \\
\hline Chenopodium album & $\cdot$ & . & $\mathrm{r}$ & $\mathrm{r}$ & + & $\mathrm{r}$ & . & . & . & + & . & . & . & . & . & . & II \\
\hline Crepis tectorum & + & + & $\mathrm{r}$ & . & + & $\mathrm{r}$ & . & . & + & . & . & . & . & . & + & + & II \\
\hline Consolida regalis & + & $\mathrm{r}$ & $\mathrm{r}$ & . & . & . & . & . & . & . & . & . & . & + & . & . & II \\
\hline Vicia villosa & $\mathrm{r}$ & + & . & . & . & . & $\mathrm{r}$ & . & + & . & . & . & . & . & . & . & II \\
\hline raphanistrum & . & . & . & . & . & . & . & . & . & + & + & . & . & . & . & . & I \\
\hline \multicolumn{18}{|c|}{ Х. в. класса Artemisetea vulgaris } \\
\hline igantea & 1 & 2 & . & . & . & . & + & 1 & + & + & . & . & + & 1 & 3 & 1 & III \\
\hline Stachys palustris & + & + & . & . & . & . & + & $\mathrm{r}$ & . & . & . & + & + & . & . & $\mathrm{r}$ & III \\
\hline Mentha arvensis & + & + & + & . & + & . & . & + & . & + & . & . & . & + & . & $\mathrm{r}$ & III \\
\hline Artemisia vulgaris & + & . & . & . & + & . & . & . & 2 & + & + & 1 & & . & + & 2 & II \\
\hline Convolvulus arvensis & . & . & + & . & . & + & . & + & . & . & . & . & + & . & . & . & II \\
\hline Hypericum perforatum & . & . & + & . & . & . & . & . & . & 1 & 1 & . & . & . & . & . & II \\
\hline Equisetum arvense & . & 1 & . & + & . & . & + & . & . & . & . & . & + & & . & . & II \\
\hline Dauc &  & . & . & $\mathrm{r}$ & . & . & . & . & $\mathrm{r}$ & 4 & 2 & . & . & . & . & . & II \\
\hline Cirsium & + & . & . & . & . & . & + & . & $\mathrm{r}$ & . & . & 1 & . & . & . & + & $\mathrm{I}$ \\
\hline vulgare & . & . & . & . & . & . & . & . & . & + & + & . & . & . & . & . & I \\
\hline \multicolumn{18}{|c|}{ Прочие виды } \\
\hline Trifolium hybridum & . & $\mathrm{r}$ & + & + & . & . & $\mathrm{r}$ & $\mathrm{r}$ & . & . & . & . & . & + & . & . & III \\
\hline Achillea millefolium & + & $\cdot$ & $\cdot$ & $\cdot$ & . & . & & & 1 & . & 1 & . & . & . & + & . & II \\
\hline Vicia cracca & $\mathrm{r}$ & . & + & . & + & . & $\mathrm{r}$ & . & . & . & . & . & $\mathrm{r}$ & . & . & . & II \\
\hline Cerastium holosteoides & . & $r$ & . & + & . & . & $\mathrm{r}$ & + & . & . & . & . & + & + & . & . & II \\
\hline Trifolium arvense & + & $\mathrm{r}$ & . & . & . & . & $\mathrm{r}$ & . & . & + & . & . & $\mathrm{r}$ & & . & $\mathrm{r}$ & II \\
\hline Plantago major & . & . & . & $\mathrm{r}$ & . & . & . & . & + & . & $\mathrm{r}$ & . & . & . & . & $\mathrm{r}$ & $\mathrm{I}$ \\
\hline Trifolium pratense & + & . & . & . & . & . & . & . & $\mathrm{r}$ & . & . & . & $\mathrm{r}$ & . & $\mathrm{r}$ & . & I \\
\hline Herniaria glabra &  & . & . & $\mathrm{r}$ & . & . & . & $\mathrm{r}$ & . & . & . &. & $\mathrm{r}$ & . & . & . & $\mathrm{I}$ \\
\hline
\end{tabular}

Примечание. Единично отмечены: Artemisia absinhtium 12 (r), Artemisia campestris 7 (1), Bromus mollis 12 (+), Campanula patula $11(\mathrm{r})$, Capsella bursa-pastoris $9(+)$, Echium vulgare 15, 16 (r), Echinochloa crus-galli 14 (1), Erigeron annuus $12(\mathrm{r})$, Erigeron acris 10, $11(+)$, Erodium cicutarum 14, $16(+)$, Fallopia dumetorum $5(+)$, Festuca rubra $6(+)$, Hieraceum umbellatum $4(+)$, Gnaphalium sylvaticum $10(\mathrm{r})$, Knautia arvensis 13 (r), Lactuca serriola $15(+)$, Leontodon autumalis 7, 8 (r), Myosotis arvensis 15, $16(1)$, Odontite vulgaris $4(+)$, Ranunculus repens $9(+)$, Persicaria maculosa $12(\mathrm{r})$, Persicaria amphibia 2, $4(\mathrm{r})$, Phleum pratense $9(+)$, Potentilla intermedia $4(+)$, Psammophiliella muralis 4, 15 (+), Rumex acetosella 7 (r), Rumex acetosa 10 $(\mathrm{r})$, Poa pratensis 12(+), Leontodon autumnalis $14(+)$, Setaria viridis $14(1)$, Spergula arvensis $14(\mathrm{r})$, Taraxacum officinale 4,9 $(+)$, Trifolium repens $4(+)$, Tussilago farfara $16(\mathrm{r})$, Vicia villosa $16(+)$.

Л о к а л и з а ц и я о п и с а н и й. Жуковский $p-н:$ 15, 16 - с. Домашово, залежь после зерновых, 10.07. 2016. Клетнянский р-н: поля заняты посевом ржи: 1-4 - с. Мужиново, 16.08.2006; 5-7 - д. Неделька, 16.08.2006; 10 - д. Добрая Корна. 4.08.2012; 11, 12 - д. Харитоновка, 18.08.2015; Новозыбковский р-н: 8 - с. Внуковичи, залежь после зерновых, 23.07.2011. 9 - д. Халеевичи, залежь после зерновых, 15.08.2016; 13, 14 - с. Старые Бобовичи, залежь после зерновых, 25.08.2010. Автор описаний: Булохов А. Д. 
Структура и видовой состав. Основу травостоя формируют Apera spica-venti и Elytrigia repens. Оба вида обычно доминируют или выступают содоминантами, они определяют и облик сообществ. Высота травостоя - 90-110 см. В составе травостоя константны, но не обильны: Centaurea cyanus, Vicia tetrasperma, Erigeron canadensis, Tripleurospermum inodorum, Sonchus arvensis, Agrostis gigantea, Stachys palustris, Mentha arvensis (табл. 1).

Общее проективное покрытие (ОПП) 40-95\%. Видовое богатство - 10-23 видов на $100 \mathrm{~m}^{2}$. В составе ценофлоры ассоциации наряду с видами класса Papaveretea rhoeadis представлен комплекс характерных видов класса Artemisetea vulgaris. Изредка с небольшим обилием встречаются луговые растения: Achillea millefolium, Trifolium pratense, Trifolium hybridum, Vicia cracca.

Местоположение и экология. Сообщества встречаются в посевах озимых и яровых зерновых культур, на парах, редко на полях с пропашными культурами. Синэкологический оптимум на песчаных и супесчаных дерново-подзолистых свежих $(5,2-5,7)$, слабокислых $(5,2-$ $5,7)$, бедных минеральным азотам $(4,0-4,5)$ почвах.

Синтаксономический анализ положения ассоциации. Сообщества ассоциации отнесены к союзу Scleranthion annui. В составе союза в Брянской области не обнаружено сообществ, которые можно было бы отнести к одной из 8 ассоциаций, установленных в Западной Европе, в частности, в Чехии: Aphano arvensis-Matricarietum chamomillae Tüxen 1937, Spergulo arvensis-Scleranthetum annui Kuhn 1937, Erophilo vernae-Arabidopsietum thalianae Kropáč in Krippelová 1981, или в Германии: Alchimelo-Matricaretum Тх. 1937, Vicetum tetraspermae Kornac 1950, Galeopso-Aphanetum arvensis Meis.1962.

Ассоциация Convolvulo arvensi-Erigeronetum canadensis ass. nov. hoc loco (табл. 2; номенклатурный тип (holotypus) - оп. 1).

X. в.: Erigeron (Conyza) canadensis (доминант), Convolvulus arvensis, Lactuca serriola.

Состав и структура. Основу травостоя формирует североамериканский вид Erigeron canadensis, в сочетании с Convolvulus arvensis, Lactuca serriola, Erigeron annuus, Taraxacum officinale aggr. На этом фоне рассеяны и другие характерные виды класса Papaveretea rhoeadis: Chenopodium album aggr., Consolida regalis, Tripleuspermum inodorum, Setaria viridis. В отдельных сообществах доминирует Setaria pumila. Общее проективное покрытие 35-95\%. Видовое богатство - 10-19 видов на $100 \mathrm{~m}^{2}$.

В составе ценофлоры ассоциации наряду с видами класс Papaveretea rhoeadis присутствуют характерные виды класса Artemisetea vulgaris, но их фитоценотическая активность невысока. 
Местоположение и экология. Сообщества ранней стадии восстановительной сукцессии на полях с полевыми культурами и на залежах 1-2 года. Синэкологический оптимум на дерновоподзолистых песчаных и супесчаных суховатых $(4,0-4,2)$, слабокислых $(5,4-5,8)$, умеренно обеспеченных минеральным азотом $(5,5-5,8)$ почвах.

Анализ синтаксономического положения ассоциации. Сообщества ассоциации включены в союз Galeopsion bifidae. В Западной Европе сообщества с константными видами Erigeron canadensis и Lactuca serriola объединяют в acc. Conyzo canadensisLactucetum serriolae Lohmeyer in Oberdorfer 1957 и включают её в союз Atriplicion Passarge 1978, порядка Sisymbrietalia Tx. ex Görs 1966. Сравнительный анализ ценофлор сообществ Conyzo canadensis-Lactucetum serriolae, описанной в г. Курске (Арепьева, 2015) и Чехии (Vegetace..., 2009) показывает, что в сообществах Брянской области отсутствуют характерные виды союза Atriplicion. Кроме того, нет в сообществах установленной ассоциации и группы характерных видов порядка Sisymbrietalia: Sisymbrium altissimum, Sisymbrium officinale, Sisymbrium loeselii, Carduus acanthoides, Hordeum murinum, Senecio viscosus, Lolium perenne, Descurainia sophia, Atriplex tatarica и др.

Ассоциация Chenopodio albi-Setarietum pumilae ass. nov. hoc loco (табл. 3; номенклатурный тип (holotypus) - оп. 8).

X. в.: Chenopodium album aggr., Echinochloa crus-galli, Setaria pumila (доминант).

Состав и структура. Основу травостоя формируют низкорослые однолетники (табл. 3). Setaria pumila создает рыжеватозеленый аспект. На этом фоне рассеяны и другие характерные виды класса Papaveretea rhoeadis: Chenopodium album, Echinochloa crusgalli, Erigeron canadensis, Raphanus raphanistrum, Viola arvensis. B составе ценофлоры ассоциации присутствуют виды класса Artemisetea vulgaris, но их фитоценотическая активность не высокая. Общее проективное покрытие 50-95\%. Видовое богатство - 10-19 видов на $100 \mathrm{M}^{2}$.

Местоположение и экология. Сообщества формируются на полях с полевыми и пропашными культурами и на залежах 1-2 года на дерново-подзолистых супесчаных и на серых лесных суглинистых свежих $(4,3-5,0)$, слабокислых $(5,2-5,6)$, хорошо обеспеченных минеральным азотом $(6,5-6,8)$ почвах.

Вариабельность. В составе ассоциации установлено 2 субассоциации (субасс.).

Субасс. Ch.a-S.p.typicum (табл. 3; оп. 1-11, номенклатурный тип (holotypus) - оп. 8.) своих дифференциальных видов не имеет. 
Таблица 2

Ассоциация Convolvulo arvensi-Erigeronetum canadensis ass. nov. hoc loco

\begin{tabular}{|c|c|c|c|c|c|c|c|c|c|c|c|c|c|c|c|c|c|}
\hline Номера описаний & 1 & 2 & 3 & 4 & 5 & 6 & 7 & 8 & 9 & 10 & 11 & 12 & 12 & 14 & 15 & 16 & Кп \\
\hline ОПП, \% & 70 & 70 & 80 & 35 & 95 & 80 & 95 & 60 & 65 & 70 & 75 & 90 & 75 & 60 & 65 & 50 & \\
\hline Число видов & 14 & 14 & 18 & 10 & 19 & 17 & 14 & 16 & 13 & 9 & 11 & 11 & 11 & 13 & 10 & 10 & \\
\hline \multicolumn{18}{|c|}{ Х. в. acc. Convolvulo arvensi-Erigeronetum canadensis } \\
\hline Erigeron canadensis & 4 & 4 & 2 & 2 & 4 & 3 & 4 & 3 & 4 & 5 & 2 & 5 & 5 & 3 & 4 & 3 & V \\
\hline Convolvulus arvensis & + & . & 1 & . & + & + & + & + & $\mathrm{r}$ & . & 1 & $\mathrm{r}$ & + & $\mathrm{r}$ & . & + & IV \\
\hline Lactuca serriola & $\mathrm{r}$ & $\mathrm{r}$ & $\mathrm{r}$ & $\mathrm{r}$ & + & . & + & . & + & $\mathrm{r}$ & . & . & . & $\mathrm{r}$ & . & $\mathrm{r}$ & IV \\
\hline \multicolumn{18}{|c|}{ Х. в. союза Galeopsion bifidae и класса Papaveretea rhoeadis } \\
\hline Chenopodium album & 1 & + & + & $\mathrm{r}$ & $\mathrm{r}$ & + & . & . & . & . & . & . & . & . & . & . & III \\
\hline Setaria pumila & + & + & + & . & 4 & 3 & . & . & . & . & . & 2 & + & . & + & . & III \\
\hline Tripleuspermum inodorum & + & $\mathrm{r}$ & . & $\mathrm{r}$ & + & $\mathrm{r}$ & . & + & . & . & . & . & . & $\mathrm{r}$ & $\mathrm{r}$ & . & III \\
\hline Setaria viridis & . & . & . & . & . & . & 1 & 1 & + & + & . & . & . & . & & . & II \\
\hline Amaranthus retroflexus & . & $\mathrm{r}$ & $\mathrm{r}$ & . & . & . & . & . & . & . & $\mathrm{r}$ & . & . & $\mathrm{r}$ & $\mathrm{r}$ & . & II \\
\hline Consolida regalis & $\mathrm{r}$ & $\mathrm{r}$ & $\mathrm{r}$ & & $\mathrm{r}$ & . & . & . & . & . & . & . & $\mathrm{r}$ & $\mathrm{r}$ & . & $\mathrm{r}$ & II \\
\hline Cirsium arvense & . & . & . & . & + & $\mathrm{r}$ & . & . & . & . & . & + & . & $\mathrm{r}$ & . & $\mathrm{r}$ & II \\
\hline Centaurea cyanus & . & $\mathrm{r}$ & . & . & . & . & . & . & . & . & + & . & . & . & $\mathrm{r}$ & . & I \\
\hline Sonchus oleraceus & $\mathrm{r}$ & . & + & . & . & . & . & . & . & . & . & . & . & . & . & . & I \\
\hline \multicolumn{18}{|c|}{ Х. в. класса Artemisietea vulgaris } \\
\hline Taraxacum officinale & . & $\mathrm{r}$ & + & $\mathrm{r}$ & + & + & + & + & + & $\mathrm{r}$ & . & + & $\mathrm{r}$ & + & + & $\mathrm{r}$ & IV \\
\hline Cichorium intybus & . & $\mathrm{r}$ & . & . & $\mathrm{r}$ & $\mathrm{r}$ & + & $\mathrm{r}$ & $\mathrm{r}$ & . & . & . & . & $\mathrm{r}$ & . & $\mathrm{r}$ & III \\
\hline Artemisia vulgaris & $\mathrm{r}$ & + & . & . & $\mathrm{r}$ & . & + & $\mathrm{r}$ & + & $\mathrm{r}$ & $\mathrm{r}$ & . & . & . & . & . & III \\
\hline Artemisia absinthium & 2 & . & $\mathrm{r}$ & $\mathrm{r}$ & . & . & . & $\mathrm{r}$ & $\mathrm{r}$ & . & . & . & $\mathrm{r}$ & $\mathrm{r}$ & . & $\mathrm{r}$ & III \\
\hline Arctium tomentosum & . & . & + & . & . & . & . & . & . & $\mathrm{r}$ & . & . & . & . & . & . & II \\
\hline Daucus carota & $\mathrm{r}$ & . & $\mathrm{r}$ & . & . & $\mathrm{r}$ & . & . & . & . & . & . & . & $\mathrm{r}$ & . & . & II \\
\hline Poa pratensis & . & + & $\mathrm{r}$ & . & . & + & . & . & . & . & + & $\cdot$ & . & . & . & . & II \\
\hline Equisetum arvense & . & . & . & . & 1 & + & + & + & . & . & 1 & + & . & & $\mathrm{r}$ & & II \\
\hline Erigeron annuus & . & . & + & . & 1 & 2 & . & . & . & . & + & $\mathrm{r}$ & + & . & $\mathrm{r}$ & . & II \\
\hline E. a. sp.septentrionalis & . & . & . & $\mathrm{r}$ & . & . & + & $\mathrm{r}$ & + & + & . & . & . & . & . & . & II \\
\hline Elytrigia repens & . & . & 1 & . & + & 1 & . & . & . & . & . & . & $\mathrm{r}$ & . & . & . & I \\
\hline Oenothera biennis & . & . & . & . & . & . & . & $\mathrm{r}$ & $\mathrm{r}$ & $\mathrm{r}$ & . & . & . & . & . & . & I \\
\hline Berteroa incana & . & . & . & + & . & . & . & 1 & . & . & . & . & . & . & + & . & I \\
\hline \multicolumn{18}{|c|}{ Прочие виды } \\
\hline Achillea millefolium & . & . & . & + & + & . & . & . & . & . & + & $\mathrm{r}$ & . & $\mathrm{r}$ & . & $\cdot$ & II \\
\hline Hieracium lactucella & . & + & $\mathrm{r}$ & . & $\mathrm{r}$ & $\mathrm{r}$ & . & . & . & . & . & . & . & . & . & . & II \\
\hline Trifolium pratense & + & . & . & . & . & . & . & . & . & + & 1 & + & . & . & . & . & II \\
\hline Trifolium arvense & . & . & . & . & + & 3 & & + & + & . & . & . & + & . & . & + & II \\
\hline Pilosella officinarum & $\mathrm{r}$ & $\mathrm{r}$ & . & . & . & . & + & $\mathrm{r}$ & $\mathrm{r}$ & . & . & . & . & . & . & . & II \\
\hline Vicia cracca & . & . & + & . & . & 1 & + & . & $\mathrm{r}$ & . & . & . & + & . & + & . & II \\
\hline
\end{tabular}

Примечание. Единично отмечены: Agrostis tenuis 1, 5 (+), Artemisia scoparia 14 (r), Geranium sibiricum 7 , $12(+)$, Plantago major 7, 8 (+), Polygonum aviculare $4(+)$, Lepidium ruderalis $8(+)$, Plantago lanceolata $12(+)$, Rumex confertus 5, 6 (r), Saponaria officinalis 5, 11 (+), Vicia sativa 3, 7 (+), Urtica dioica 13, 16 (r).

Локализация описаний. Жуковский р-н: 1, 2 - д. Мареевка, залежь, 4.08.2014; Клетнянский p-н: 4, 5 - д. Строительная слобода, залежь, 14.08.2015. 6 - д. Николаевка, залежь 23.08.2015; 7, 8 - д. Ширковка, залежь, 14.09. 2011; 9 - д. Харитоновка, залежь, 2.07.2009; 10 - с. Мужиново, залежь, 23.08.2012. Комарический р-н: 11 - с. Угревище, поле под паром, 8.07.2013; 12 - с. Угревище, пустырь, 8.07.2013; 13 с. Угревище, окраина заброшенной фермы, 8.07.2013; 14 - с. Угревище, поле под паром, 12.07.2013. Севский p-н: 15 - с. Чемлыж, поле под паром, 12.07.2015. Трубчевский $p$-н, 16 - с. Кветунь, поле под паром, 18.07.2015. Авторы описаний: 1-10 - Булохов А. Д., 11-16 - Ивенкова И.М. 
Местоположение и экология. Сообщества распространены в посевах полевых культур и на залежах 1-2-летнего возраста или парах, реже это рудеральные сообщества вдоль полевых дорог и на пустырях. Синэкологический оптимум на суховатых $(4,3-4,5)$, слабокислых $(6,2-$ $6,5)$, хорошо обеспеченных минеральным азотом $(6,8-7,0)$ супесчаных и суглинистых дерново-подзолистых и серых лесных почвах. Субасс. Ch.a-S.p. lepidietosum densifloris subass. nov. hoc loco (табл. 3; оп.1216, номенклатурный тип (holotypus) оп. - 14).

X. в.: Lepidium densiflorum, Berteroa incana, Setaria viridis, Anisantha tectorum. В травостое доминирует Setaria pumila. Изредка встречаются: Erigeron annuus, Echium vulgare, Medicago falcata. Единично встречаются: Amaranthus albus, Draba nemorosa, Lappula

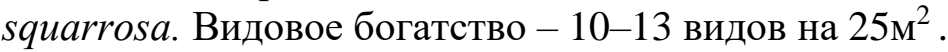

Местообитание и экология. Термофильные рудеральные сообщества, распространенные вдоль ж. д. на щебнисто-песчаных субстратах.

Синтаксономическое положение ассоциации. В Западной Европе описана acc. Setario pumilae-Echinochloёtum crurisgalli Felföldy 1942 corr. Mucina in Mucina et al. 1993. Она отнесена к союзу Spergulo arvensis-Erodion cicutariae J. Tüxen in Passarge 1964 (класс Digitario sanguinalis-Eragrostietea minoris Mucina, Lososova et Silc 2016). Х.в. этой ассоциации: Echinochloa crus-galli, Galinsoga parviflora, Setaria pumila, S. viridis (доминанты). Анализ ценофлоры ассоциации показал, что в ней присутствует всего два характерных вида этого класса Digitario sanguinalis-Eragrostietea minoris: Echinochloa crus-galli и Lepidium densiflorum с незначительным обилием-покрытием. Ценофлору асc. Chenopodio albi-Setarietum pumilae формируют характерные виды класса Papaveretea rhoeadis и Artemisietea vulgaris. Нет основания помещать ассоциацию в союз Spergulo arvensis-Erodion cicutariae и класс Digitario sanguinalisEragrostietea minoris.

Ассоциация Setario pumilae-Galinsogetum parviflorae Tx.50 em. Müller et Oberd. in Oberd.83 (табл. 4).

Х. в.: Galinsoga parviflora (доминант), Echinochloa crus-galli, Galeopsis speciosa, Persicaria lapathifolia, Stachys palustris, Setaria pumila

Объединяет сообщества, формирующиеся на картофельных полях. В составе ценофлоры константны однолетники: Chenopodium album, Amaranthus retroflexus. Облик сообществ определяет Galinsoga parviflora, активно распространяющийся североамериканский сорняк пропашных культур, определяющий зеленовато-белый аспект фитоценозов в конце июля - начале августа. 
Таблица 3

Ассоциация Chenopodio albi-Setarietum pumilae

\begin{tabular}{|c|c|c|c|c|c|c|c|c|c|c|c|c|c|c|c|c|c|c|c|}
\hline \multirow{4}{*}{\begin{tabular}{|l} 
Субассоциации \\
Номера описаний \\
ОПП, \% \\
Число видов
\end{tabular}} & \multicolumn{11}{|c|}{ typicum } & \multicolumn{5}{|c|}{$\begin{array}{c}\text { lepidietosum } \\
\text { densiflori }\end{array}$} & \multirow{3}{*}{\multicolumn{3}{|c|}{ Кп }} \\
\hline & \multirow{3}{*}{\multicolumn{2}{|c|}{$\begin{array}{cc}1 & 2 \\
60 & 5 \\
11 & 1 \\
\end{array}$}} & \multirow{3}{*}{$\begin{array}{cc}2 & 3 \\
50 & 60 \\
1 & 9 \\
\end{array}$} & \multirow{3}{*}{$\begin{array}{c}4 \\
95 \\
18 \\
\end{array}$} & \multirow{3}{*}{$\begin{array}{c}5 \\
80 \\
13 \\
\end{array}$} & \multirow{3}{*}{$\begin{array}{c}6 \\
95 \\
13 \\
\end{array}$} & \multirow{3}{*}{$\begin{array}{c}7 \\
95 \\
13 \\
\end{array}$} & \multirow{3}{*}{$\begin{array}{c}8 \\
60 \\
18\end{array}$} & \multirow{3}{*}{$\begin{array}{c}9 \\
60 \\
15 \\
\end{array}$} & \multirow{3}{*}{$\begin{array}{l}10 \\
80 \\
17\end{array}$} & \multirow{3}{*}{$\begin{array}{c}11 \\
65 \\
15\end{array}$} & \multirow{3}{*}{$\begin{array}{l}12 \\
60 \\
13\end{array}$} & \multirow{3}{*}{$\begin{array}{c}13 \\
70 \\
9\end{array}$} & \multirow{3}{*}{$\begin{array}{l}14 \\
70 \\
12\end{array}$} & \multirow{3}{*}{$\begin{array}{l}15 \\
70 \\
10 \\
\end{array}$} & \multirow{3}{*}{$\begin{array}{c}16 \\
80 \\
12\end{array}$} & & & \\
\hline & & & & & & & & & & & & & & & & & & & \\
\hline & & & & & & & & & & & & & & & & & $\mathrm{ac}$ & $\mathrm{a}$ & 6 \\
\hline & & B. ac & c. $C l$ & eno & odic & $a l b$ & Setc & riets & $m p$ & imil & & & & & & & & & \\
\hline Setaria pumila & 3 & 2 & 2 & 3 & 5 & 5 & 5 & 4 & 4 & 4 & 4 & 3 & 4 & 3 & 3 & 4 & $\mathrm{~V}$ & $\mathrm{~V}$ & 5 \\
\hline Chenopodium album & 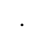 & . & + & + & $\mathrm{r}$ & $\mathrm{r}$ & $\mathrm{r}$ & + & + & + & $\mathrm{r}$ & + & . & + & + & + & IV & IV & 4 \\
\hline Echinochloa crus-galli & $\mathrm{r}$ & 1 & + & . & + & 1 & + & 1 & 1 & $\mathrm{r}$ & . & . & . & . & . & . & III & $\mathrm{V}$ & \\
\hline & & & B. c. & бас & lep & diet & sun & den & siflo & & & & & & & & & & \\
\hline Lepidium densiflorum & . &  &  & & . & . & & 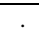 & . & 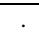 & & + & + & + & + & $\mathrm{r}$ & II & & 5 \\
\hline Berteroa incana & . & . & . & . & . & . & . & . & . & . & . & + & + & + & $\mathrm{r}$ & . & II & & 4 \\
\hline Setaria viridis & . & . & & & . & . & & . & . & . & . & 1 & + & . & . & + & I & & 3 \\
\hline Anisantha tectorum & & & & & & . & & & . & & & & 1 & + & . & + & $\mathrm{I}$ & & 3 \\
\hline & ою3 & $\mathrm{Ga}$ & leops & ion & ifidc & $e$ и & слас & $\mathrm{aPa}$ & pave & retec & rho & adis & & & & & & & \\
\hline Convolvulus arvensis & + & . & 1 & + & + & $\mathrm{r}$ & + & + & + & . & . & + & + & . & . & . & IV & V & 2 \\
\hline Galeopsis bifida & . & + & & $\mathrm{r}$ & + & $\mathrm{r}$ & . & . & . & . & . & . & . & . & . & . & II & III & \\
\hline Delphinium consolida & . & . & . & . & $\mathrm{r}$ & $\mathrm{r}$ & + & . & $\mathrm{r}$ & $\mathrm{r}$ & . & . & . & . & . & . & II & III & \\
\hline Tripleurospermum inodorum & . & . & . & $\mathrm{r}$ & . & $\mathrm{r}$ & $\mathrm{r}$ & + & + & . & . & . & . & . & . & . & II & III & \\
\hline Amaranthus retroflexus & . & . & $\mathrm{r}$ & . & . & 1 & + & . & . & . & . & + & + & . & . & + & II & II & 2 \\
\hline Sonchus oleraceus & . & + & $\mathrm{r}$ & $\mathrm{r}$ & . & . & . & . & . & + & . & . & . & . & . & . & II & II & \\
\hline Erigeron annuиs & . & . & . & . & . & . & . & + & + & . & . & . & . & . & + & + & II & II & 2 \\
\hline Raphanus raphanistrum & + & . & . & . & . & $\mathrm{r}$ & & + & . & . & + & + & . & $\mathrm{r}$ & . & . & II & II & 2 \\
\hline Viola arvensis & + & . & . & . & . & . & + & . & . & + & + & . & . & . & . & . & II & I & \\
\hline Elytrigia repens & 1 & . & . & . & . & + & . & + & . & 1 & . & . & . & . & . & . & II & II & \\
\hline Erigeron canadensis & . & . & . & + & . & . & . & . & + & 1 & . & + & . & . & + & + & II & I & 2 \\
\hline Polygonum aviculare & . & . & . & . & . & . & $\mathrm{r}$ & + & + & . & + & . & . & . & . & . & II & II & \\
\hline Gypsophyla muralis & . & . & . & + & . & . & . & . & . & + & + & . & . & . & . & . & I & II & \\
\hline Galeopsis speciosa & . & . & . & $\mathrm{r}$ & . & . & . & . & + & . & . & . & . & . & . & . & I & II & \\
\hline Centaurea cyanus & . & $\mathrm{r}$ & . & $\mathrm{r}$ & . & . & . & . & . & . & . & . & . & . & . & . & I & II & \\
\hline Crepis teucrium & . & . & . & . & + & . & + & . & . & . & . & . & . & . & . & . & I & II & \\
\hline Sonchus arvensis & . & . & . & . & . & . & . & + & + & . & . & . & . & . & . & . & I & II & \\
\hline Thlaspi arvensis & & + & 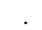 & & + & . & & . & . & . & . & . & . & . & . & 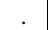 & I & II & \\
\hline & & & X. в. & клас & $\mathrm{ca}$ & tem & siete & $a v u$ & gari & & & & & & & & & & \\
\hline Artemisia vulgaris & . & $\cdot$ & . & . & $\mathrm{r}$ & $\mathrm{r}$ & + & . & $\mathrm{r}$ & + & . & . & . & . & . & . & II & II & \\
\hline Cichorium intybus & . & . & . & $\mathrm{r}$ & . & . &. & . & $\mathrm{r}$ & . & . & + & . & . & $\mathrm{r}$ & . & II & II & 2 \\
\hline Mentha arvensis & + & $\mathrm{r}$ & . & $\mathrm{r}$ & . & . & . & . & . & + & . & . & . & . & . & . & II & II & \\
\hline Plantago major & + & . & . & . & + & . & + & & $\mathrm{r}$ & + & . & . & . & . & . & . & II & III & \\
\hline Achillea millefolium & $\mathrm{r}$ & . & . & . & . & . & . & + & + & . & . & . & . & + & . & . & II & II & 1 \\
\hline Artemisia absinthium &  & . & . & . & . & . & $\mathrm{r}$ & . & . & $\mathrm{r}$ & . & . & $\mathrm{r}$ & . & . & . & I & I & 1 \\
\hline Stachys palustris & & + & & $\mathrm{r}$ & + & . & & & & & & 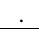 & 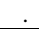 & &  & & I & II & \\
\hline
\end{tabular}

Примечание. ас - Кп ассоциации Chenopodio albi-Setarietum pumilae, a - Кп субассоциации typicum, $6-$ Кп субассоциации lepidietosum densiflori. Единично отмечены: Amaranthus albus 13 (+), Atriplex patula 11 (r), Capsella bursa-pastoris 12 (r), Dactylis glomerata 11 (+), Daucus carota 5 (r), Draba nemorosa 14 (+), Dracocephalum thymiflorum $14(+)$, Echium vulgare 14, 15 (r), Erodium cicutarum 2, $10(+)$, Equisetum arvensis 1, 4 (+), Euphorbia virgata 4, 14 (+), Fallopia convululus 1 (1), 11 (+), Galinsoga parviflora 8 (r), Geranium sibiricum 16 (+), Gnaphalium uliginosum 10 (r), 11 (+), Lactuca serriola 11 (r), Lappula squarrosa 14 (+), Linaria vulgaris $16(+)$, Medicago falcata 12 (r), $15(+)$, Medicago lupulina 15 (r), Silene latifolia 3 (r), $11(+)$, Melilotus albus 11 (r), Oxalis fontana 4 (r), Papaver dubium 16 (+), Potentilla argentea 12 (r), Scleranthus annus 3 (+), Sisymbrium loeselii 16 (+), Solanum nigrum 6, 12 (r), Spergula arvensis 4, $11(+)$, Stachys annua $6(+)$, Taraxacum officinale 12 (r), Trifolium arvense 4, 10 (+), Trifolium hybridum $5(+)$, Trifolium pratense 2, $10(+)$, Trifolium repens $11(+)$, Vicia tetrasperma $2(+), 10$ (r).

Локализация описаний. Выгоничский р-н: 1, 2 - окр. д. Сосновка, залежь, 26.07.2013. Жуковский р-н: 3, 4 с. Алешня, ячменное поле, 22.08.2005; 5, 6 - с. Леднево, овсяное поле, 22.08.2016. Клетнянский р-н: 7, 8с. Мужиново, ржаное поле, 7.08.2015. Комаричский р-н: 9, 10 - с. Дерюгино, залежь, 17.08.2011; 11 - с. Евдокимовка, залежь, 18.08.2015. Трубчевский $p-н: \mathbf{1 2}$ - окрестности пос. Белая Березка, песчаная насыпь вдоль ж.д.; 05.08.2013. Г. Брянск: 13 - ст. Красный Профинтерн, насыпь вдоль ж.-д., 22.08.2015; 14 - ст. Мальцевская, насыпь вдоль ж.д., 22.08.2015. Г. Карачев: 15 -, насыпь вдоль ж.-д., 4.07.2012. Г. Почеп: 16 , насыпь вдоль ж.д., 25.08.2015. Авторы описаний: 1-8 - Булохов А.Д., 9-11 - Ивенкова И.М., 12-16 Панасенко Н.Н.

Общее проективное покрытие - 90-100\%. В составе ценофлоры отмечено 37 видов, однолетники составляют 54,0\%.

Местообитание и экология. Сообщества распространены на

$-111-$ 
картофельных полях по всей территории области. Синэкологический оптимум на свежих $(4,7-5)$, слабокислых и нейтральных $(7,2)$ богатых минеральным азотом $(7,2)$ супесчаных и суглинистых дерновоподзолистых почвах.

Общее проективное покрытие - 90-100\%. В составе ценофлоры отмечено 37 видов, однолетники составляют 54,0\%.

Местообитание и экология. Сообщества распространены на картофельных полях по всей территории области. Синэкологический оптимум на свежих $(4,7-5)$, слабокислых и нейтральных $(7,2)$ богатых минеральным азотом $(7,2)$ супесчаных и суглинистых дерновоподзолистых почвах.

Таблица 4

Ассоциация Setaria pumilae-Galinsogetum parviflorae

\begin{tabular}{|l|cccccc|c|}
\hline & 1 & 2 & 3 & 4 & 5 & Кп \\
ОПП ,\% & 100 & 100 & 100 & 100 & 90 & \\
Число видов & 15 & 17 & 18 & 22 & 15 & \\
\hline \multicolumn{1}{|c|}{ X. в. acc. Setaria pumilae-Galinsogetum parviflorae } \\
\hline Galinsoga parviflora & 5 & 5 & 5 & 1 & 3 & V \\
Echinochloa crus-galli & + & + & + & 2 & + & V \\
Setaria pumila & 1 & 2 & + & + & 1 & V \\
Galeopsis speciosa & 1 & + & 1 & + &. & IV \\
Persicaria lapathifolia & 1 & + & + & + &. & IV \\
Stachys palustris & 1 & + & 1 & + &. & IV \\
\hline
\end{tabular}

Stachys palustris

Galeopsis bifida

X. в. союза Galeopsion bifidae

Erodium cicutarum

Fallopia convolvulus

Stellaria media

Lycopsis arvensis

\begin{tabular}{ccccc|c}
+ & + & + & + & $\cdot$ & IV \\
1 & + & $\cdot$ & $\cdot$ & + & III \\
$\cdot$ & $\cdot$ & + & + & + & III \\
$\cdot$ & $\cdot$ & 2 & 3 & $\cdot$ & II \\
$\cdot$ & r & $\cdot$ & $\cdot$ & + & II \\
\hline
\end{tabular}

Chenopodium album

Amaranthus retroflexus

Erysimum cheiranthoides

Capsella bursa-pastoris

Sonchus arvensis

Tripleurospermum inodorum

Viola arvense

Х. в. класса Papaveretea rhoeadis

Х. в. класса Artemisietea vulgaris

Cirsium arvense

Vicia villosa

Artemisia vulgaris

Equisetum arvense

Примечание. Единично отмечены: Centaurea cyanus 5 (1), Crepis teucrium 5 (r), Elytrigia repens 4 (1), Elsholtzia ciliata $3(+)$, Fumaria officinalis $4(+)$, Gnaphalium uliginosum $4(\mathrm{r})$, Herniaria polygama $4(+)$, Silene latifolia $4(+)$, Mentha arvensis $2(+)$, Raphanum raphanistrum $5(+)$, Spergula arvensis $5(+)$, Taraxacum officinale $3(+)$, Thlaspi arvense $4(+)$, Viscaria behen $5(\mathrm{r})$, Vicia tetrasperma $3(+)$.

Локализация описаний. Жуковский р-н: $\mathbf{4}$ - д. Ходиловичи, картофельное поле, 15.08.2014. Клетнянский pн: 1-2 - с. Мужиново, картофельное поле, $1.08 .2005 ; \mathbf{3}$ - д. Бульшево, картофельное поле, 15.08.2016.

Суражский р-н: 5 - с. Дубровка, картофельное поле, 20.08.2017. Автор Булохов А. Д. 
Таблица 5

Ассоциация Artemisio vulgaris-Tripleurospermetum inodori ass. nov. hoc loco

\begin{tabular}{|c|c|c|c|c|c|c|c|c|c|c|c|c|c|}
\hline \multirow{2}{*}{\begin{tabular}{|l|} 
Варианты \\
Номера описаний \\
\end{tabular}} & \multicolumn{4}{|c|}{$\begin{array}{c}\text { Arabidopsis } \\
\text { thaliana }\end{array}$} & \multicolumn{6}{|c|}{ typica } & \multicolumn{3}{|c|}{ Кп } \\
\hline & 12 & 3 & 4 & 5 & 6 & 7 & 8 & $9 \quad 10$ & 01 & 1112 & & & \\
\hline ОПП, $\%$ & \multicolumn{13}{|c|}{$\begin{array}{lllllllllllll}90 & 95 & 80 & 90 & 85 & 75 & 50 & 50 & 80 & 95 & 95 & 70\end{array}$} \\
\hline Число видов & 2420 & 14 & 20 & 13 & 16 & 13 & 22 & 1412 & 2 & 1111 & ac & $\mathbf{a}$ & б \\
\hline \multicolumn{14}{|c|}{ Х. в. acc. Artemisio vulgaris-Tripleurospermetum inodori } \\
\hline Tripleurospermum inodorum & 55 & 3 & 5 & 4 & 2 & 4 & 2 & 41 & 1 & +1 & $\mathrm{~V}$ & $\mathrm{~V}$ & $\mathrm{~V}$ \\
\hline Artemisia vulgaris & $1+$ & $\mathrm{r}$ & + & + & $\mathrm{r}$ & + & + & +2 & 2 & 22 & $\mathrm{~V}$ & $\mathrm{~V}$ & V \\
\hline Capsela bursa-pastoris & 11 & 3 & 1 & 1 & + & + & + & $1+$ & + & ++ & V & $\mathrm{V}$ & V \\
\hline \multicolumn{14}{|c|}{ Д. в. варианта Arabidopsis thaliana } \\
\hline Arabidopsis thaliana & $+\quad+$ & & & & . & . & . & . & & . & II & $\mathrm{V}$ & \\
\hline Stellaria media & & + & 1 & & . & $\mathrm{r}$ & . & . & . & . & III & $\mathrm{V}$ & I \\
\hline Crepis tectorum & & $\mathrm{r}$ & + & . & . & . & . & . & & & II & IV & \\
\hline Brassica campestris & & . & $\mathrm{r}$ & . & . & . & $\mathrm{r}$ & . & & . & II & III & I \\
\hline Galeopsis bifida & & $\mathrm{r}$ & $\mathrm{r}$ & & & $\mathrm{r}$ & & - & & . & II & III & $\mathrm{I}$ \\
\hline \multicolumn{14}{|c|}{ Х. в. союза Oxalidion europaeae } \\
\hline Chenopodium album & & + & $\mathrm{r}$ & + & 1 & $\mathrm{r}$ & 3 & & & 1 & $\mathrm{~V}$ & IV & $\mathrm{V}$ \\
\hline Cirsium arvense & & + & $\mathrm{r}$ & . & + & . & 1 & + & . & 1 & IV & IV & III \\
\hline Sonchus oleraceus & & + & + & $\mathrm{r}$ & + & . & + & . & + & + & IV & IV & III \\
\hline Convolvulus arvensis & $1+$ & . & + & 1 & . & . & $\mathrm{r}$ & + & . & & III & III & II \\
\hline Роа аппиа & & . & $\mathrm{r}$ & + & 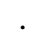 & . & + & . & 1 & & III & III & II \\
\hline Erysimum cheirantoides & . . & . & . & & + & . & + & . & & & $\mathrm{I}$ & & II \\
\hline \multicolumn{14}{|c|}{ Х. в. класса Papaveretea rhoeadis } \\
\hline Elytrigia repens & & & + & & 1 & + & 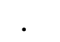 & . & 1 & & III & III & III \\
\hline Erigeron canadensis & & . & 1 & + & 2 & 1 & + & + & . & & III & II & III \\
\hline Raphnus raphanistrum & + & . & . & . & $\mathrm{r}$ & $\mathrm{r}$ & + & . & . & & II & I & III \\
\hline Viola arvensis & $\mathrm{r}$ & . & $\mathrm{r}$ & . & $\cdot$ & . & 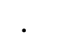 & . & . & & I & II & \\
\hline Stachys palustris & . & . & . & $\mathrm{r}$ & . & . & & + & & & I & $\mathrm{I}$ & I \\
\hline Linaria vulgaris & $\mathrm{r}$ & . & . & . & $\mathrm{r}$ & . &  & . & . & & $\mathrm{I}$ & $\mathrm{I}$ & $\mathrm{I}$ \\
\hline Lactuca serriola & . & . & . & . & . & . & + & + & . & & I & & II \\
\hline Erigeron anuuus & . 1 & & . & & & + & & . & & & $\mathrm{I}$ & $\mathrm{I}$ & I \\
\hline \multicolumn{14}{|c|}{ Х. в. класса Artemisietea vulgaris } \\
\hline Taraxacum officinale & $+\quad+$ & 2 & + & . & & + & & +3 & 3 & 3 & IV & IV & IV \\
\hline Equisetum arvense & & + & 1 & + & 1 & $\mathrm{r}$ & 1 & + & . & . & IV & $\mathrm{V}$ & II \\
\hline Achillea millefolium & $+r$ & . & $\mathrm{r}$ & + & . & + & 1 & . & + & + & IV & IV & III \\
\hline Poa trivialis & & + & . & . & + & . & + & & 2 & & III & $\mathrm{I}$ & III \\
\hline Melilotus albus & . & . & . & $\cdot$ & . & . & $\mathrm{r}$ & $\mathrm{r}$ & r & & III & & $\mathrm{V}$ \\
\hline Lotus corniculatus & & . & & . & . & . & . & . & $\mathrm{r}$ & & I & & II \\
\hline Euphorbia virgata & & . & & . & + & . & $\mathrm{r}$ & & & & I & & II \\
\hline Cichorium intybus & . . & & . & & & . & & $\mathrm{r}$ & & 2 & I & & II \\
\hline
\end{tabular}

Примечание. ас - Кп ассоциации Artemisio vulgaris-Tripleurospermetum inodori, а - Кп варианта Arabidopsis thaliana, б - Кп варианта typica. Единично отмечены: Arctium tomentosum 11 (+), Agrostis gigantea $2(+)$, Atriplex sagittata 11 (+), Carlina bibersteinii 9 (r), Delphinium consolida 8 (r), Echinochloa crusgalli 6 (+), Erodium cicutarum 9 (r), Fumaria officinalis 4 (r), Galeopsis speciosa 8 (r), Gypsophila muralis 2 (r), Hieracium sp. 1 (r), Mentha arvensis 1 (r), Phleum pratense 1 (r), Rarnunculus repens 1 (r), Rumex crispus $1(+)$, Tanaceum vulgare $6(+)$, Thlaspi arvense 8 (r), Trifolium arvense $1(+)$, Trifolium hybridum 1 (+), Trifolium pratense $1(\mathrm{r})$, Vicia cracca $8(\mathrm{r})$, Urtica dioica $11(+)$.

Локализация описаний. Брянский р-н: 3-5 - пос. Супонево, заброшенные дачные участки, 22.06.2012; 6-9 - пос. Добрунь, залежь, 5.07.2013; 10, 11 - пос. Тиганово, 23.06. 2016; 11-13 - пос. Елисеевичи, залежь на бывших пропашных культур, 12.08.2017. Г. Брянск: 1, 2 - Советский р-н, дачный кооператив «Калинка», заброшенные дачные участки, 12.07.2009. Автор Булохов А. Д. 
Ассоциация Artemisio vulgaris-Tripleurospermetum inodori ass. nov. hoc loco (табл. 5; номенклатурный тип (holotypus) - oп. 7).

X. в.: Artemisia vulgaris, Capsella bursa-pastoris, Tripleurospermum inodorum.

Состав и структура. Основу травостоя формируют однолетники. Доминирует Tripleurospermum inodorum, создающий в период цветения желтовато-белый аспект. В составе ценофлоры ассоциации наряду с видами класса Papaveretea rhoeadis (Capsella bursa-pastoris, Chenopodium album, Erigeron canadensis) присутствуют характерные виды класса Artemisetea vulgaris, но их фитоценотическая значимость небольшая. Общее проективное покрытие 50-95\%. Видовое богатство - 11-24 вида на $100 \mathrm{~m}^{2}$.

Местоположение и экология. Сообщества ранней стадии восстановительной сукцессии на полях с пропашными, реже полевыми культурами. Распространены по залежам 1-2 года на серых лесных суглинистых свежих $(4,3-5,0)$, слабокислых $(5,2-5,6)$, хорошо обеспеченных минеральным азотом $(6,5-6,8)$ почвах. Tripleurospermum inodorum на 2-3 год вытесняется из сообществ Artemisia vulgaris, Elytrigia repens, Cirsium arvense, Taraxacum officinale aggr.

Вариабельность. В составе синтаксона установлено 2 варианта.

Вариант Arabidopsis thaliana (табл. 5, оп. 1-5). Дифференциальные виды (Д. в.): Arabidopsis thaliana, Stellaria media, Crepis tectorum, Galeopsis bifida, Brassica campestris. Сообщества варианта формируются на залежах первого года или на пару, представляют первую стадию восстановительной сукцессии.

Вариант typica (табл. 5, оп. 6-12) представляет более поздние стадии восстановительной сукцессии и своих дифференциальных видов не имеет. В ценофлоре появляются виды класса Artemisietea vulgaris: Cichorium intybus, Elytrigia repens, Poa trivialis, Melilotus albus.

Класс Sisymbrietea Gutte et Hilbig 1975

Объединяет разнородную антропогенную растительность с преобладанием однолетников, разнообразных нарушенных местообитаний, а также пропашных и полевых культур в умеренных областях Евразии. В составе класса один порядок Sisymbrietalia J. Тх. ex Görs 1966 и союз Atriplicion Passarge 1978. Союз объединяет сообщества, формирующиеся на рудеральных местообитаниях.

Ассоциация Sisymbrietum loeselii (Krech 1935) Gutte 1972 (табл. 6, оп. 1-8)

Х. в. Sisymbrium loeselii (доминант). 
Состав и структура. Основу травостоя формирует Sisymbrium loselii, создающий в период цветения ярко-желтый аспект. На этом фоне рассеяны Artemisia vulgaris, Erigeron canadensis, Crepis tectorum, Lepidium densiflorum и другие характерные виды класса Sisymbrietea Gutte et Hilbig 1975. В сообществах высотой до 1,5 м наряду с Sisymbrium loeselii, субдоминантами иногда выступают Erigeron canadensis, Elyrtigia repens.

Таблица 6

Ассоциация Sisymbrietum loselii и сообщество Sisymbrium volgense

\begin{tabular}{|c|c|c|c|c|c|c|c|c|c|c|c|c|c|}
\hline $\begin{array}{l}\text { Номера описанпй } \\
\text { ОПII, \% }\end{array}$ & \multirow{2}{*}{\multicolumn{10}{|c|}{\begin{tabular}{|ccccccccccc}
1 & 2 & 3 & 4 & 5 & 6 & 7 & 8 & 9 & 10 & 11 \\
80 & 80 & 75 & 70 & 90 & 90 & 95 & 99 & 90 & 80 & 90 \\
10 & 10 & 8 & 10 & 12 & 14 & 15 & 11 & 12 & 10 & 10 \\
\end{tabular}}} & & \multicolumn{2}{|c|}{ KП } \\
\hline Чнсло вшдов & & & & & & & & & & & $a$ & & a \\
\hline \multicolumn{14}{|c|}{ X. в acc. Sisymbrietum loeselii } \\
\hline Sisymbrium loeselii & 5 & 5 & 55 & 5 & 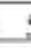 & 5 & 5 & & & & IV & & \\
\hline \multicolumn{14}{|c|}{ Сообщество Sisymbrium volgense } \\
\hline Sisymbrium volgense & & & & & & & & & & 44 & & & 3 \\
\hline \multicolumn{14}{|c|}{ Х. в. вшцы союза Atriplicion, порядка Sisymbrietalia sophiae и класса Sisymbrietea } \\
\hline Artemisis vulgaris & $r-$ & + & . . & + & 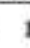 & + & + & & &.$\quad$. & & & 1 \\
\hline ensis & 12 & 2 & 2. & + & - & + & . & & & . . . & I & & 1 \\
\hline Crepis tectorum & +- & +- & ++ & + & - & . & . & & & . . & I & & \\
\hline Matricaria perforata & & . & .. . & + & t & + & + & & & & II & & \\
\hline Lepidinm densiflorum & & . & . . & + & - & + & + & & & . . & II & & \\
\hline mlgaris & & . & . : & . & 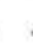 & $\mathrm{r}$ & . & & & & II & & 3 \\
\hline a absinthium & & $\therefore$. & r. & . & & . & . & & & r & I & & 2 \\
\hline Comolvulus arvensis & & & + . & . & & . & + & & & $1+$ & I & & 3 \\
\hline Elyrtigia repens & & . & . . & + & & + & 2 & & & r 1 & I & & 2 \\
\hline Lactuca serriola & & . & . . & . & & + & + & & & + & I & & 1 \\
\hline Capsella bursa pastoris & & . & . . & + & - & + & . & & & & I & & \\
\hline Rumex thyrsiflorus & + & . & & . & & . & . & & & r. & I & & 1 \\
\hline a incana & & & & \pm & & + & + & & & & I & & \\
\hline \multicolumn{14}{|c|}{ Прочие виды } \\
\hline Bromopsis inermis & & & & & & & . & & & . 2 & I & & \\
\hline Medicago falcata & & . & . + & . & & . & . & & & $2+$ & I & & 2 \\
\hline Tragopogon dubium & +1 & $\mathrm{r}$ & , + & $0^{\circ}$ & & . & . & & & . . & 1 & & 1 \\
\hline Acetosella vulgaris & & . & . . & + & t. & + & . & & & . . & I & & \\
\hline Calamagrostis epigeios & & . & . . & 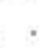 & & + & . & & & $r+$ & I & & 2 \\
\hline Medicago sativa & & & . $r$ & & & & & & & & & & 2 \\
\hline
\end{tabular}

Примечание. ас - Кп ассоциации Sisymbrietum loeselii, а - Кп сообщества Sisymbrium volgense. Единично отмечены: Apera spica-venti $5(+)$, Artemisia campestris 2 (r), 4 (+), Carex praecox 10 (1), Descurania sophia $6(\mathrm{r})$, Echium vulgaris $8(+)$, Erigeron annuus 9 (r), Erysimum chieranthoides 6, $7(+)$, Erysimum repandrum 6 (r), Euphorbia virgata 2 (r), Gallium mollugo 3, 10 (r), Lathyrus pratensis 10 (r), Lepidium densiflorum 7 (r), Melandrium album 6, 8 (+), Melilotus officinalis 2 (r), 11 (+), Silene vulgaris 2 (r), Oenothera biennis 5 (r), Poa pratensis 6, $8(+)$, Peucedanum oreoselinum 4 (r), Trifolium arvense 6 (r), Vicia vilosa $7(\mathrm{r})$, Saponaria officinalis $9(+)$, Verbascum lychnitis $1(+), 3(\mathrm{r})$, Vicia cracca $2(+)$, Viola tricolor $4(+), 7$ (r).

Локализация описаний. Г. Брянск: 1-4 - пл. 5 км, ж.-д. насыпь, 30.08.2016; 5-8 - пл. Брянск-Восточный, ж.-д. насыпь, 18.06. 2017; 9-11 -пл. 5 км - ст. Брянск II, ж.-д. насыпь, 30.08.2013. Автор Булохов А. Д.

Местоположение и экология. Сообщества ассоциации распространены по слабонаклонным откосам ж.д. и вскрытым 
супесчаным субстратам вдоль ж.-д. насыпей. В регионе встречаются достаточно редко.

Вариабельность. Сравнение ценофлор западноевропейских сообществ и распространенных в Южном Нечерноземье показывает их существеннее различие. В составе ценофлоры ассоциации в Южном Нечерноземье отсутствуют: Cardaria draba, Lolium perenne, Sisymbrium officinale, Sisymbrium altissimum, Carduus acanthoides, Hordeum murinum. Фактически характерным диагностическим видом является только Sisymbrium loeselii.

Сообщество Sisymbrium volgense [Sisymbrietalia sophiae] (табл. 6, оп. 9-11).

Х. в. Sisymbrium volgense (доминант).

Опознается по доминированию Sisymbrium volgense, который определяет облик сообществ и создает желтый аспект. Sisymbrium volgense - заносный степной вид, спорадически распространенный на территории региона по антропогенным местообитаниям. Нередко содоминантами выступают: Bromopsis inermis, Artemisia absinthium, Tanacetum vulgaris, Medicago falcata, Medicago sativa. Сообщества распространены на супесчано-суглинистых субстратах вдоль ж.д. Обнаружены только в г. Брянске.

Ассоциация Atriplici patulae-Tripleurospermetum inodori ass. nov. hoc loco (табл. 7; номенклатурный тип (holotypus) - оп. 2).

X. в.: Atriplex patula, Tripleurospermum inodorum.

Состав и структура. Основу травостоя формируют однолетники, обычно доминирует Tripleurospermum inodorum, создающий желто-белый аспект. Содоминанты - Atriplex patula, Chenopodium album. Константы, но не обильны: Capsella bursapastoris, Crepis tectorum, Poa annua, Sonchus arvensis. В составе травостоя встречаются луговые виды, семена которых заносятся из балок, прилегающих к полям: Trifolium pratense, Phleum pratense, Poa palustris, Poa angustifolia. Общее проективное покрытие 80-90\%. Видовое богатство - 16-21 вид на $100 \mathrm{~m}^{2}$.

Местоположение и экология. Сообщества ранней стадии восстановительной сукцессии на молодых залежах и полях с пропашными, реже полевыми культурами. Приурочены к серым лесным суглинистым свежим $(4,3-5,0)$, слабокислым $(5,2-5,6)$, хорошо обеспеченным минеральным азотом $(6,5-6,8)$ почвам. Уже на 2-3 год Artemisia vulgaris, Elytrigia repens, Cirsium arvense вытесняют Tripleurospermum inodorum из сообществ.

Синтаксономическое положение ассоциации. Сообщества синтаксона отнесены к союзу Atriplicion Passarge 1978 по характерным 
видам. Но в региональных сегетальных сообществах обычно отсутствуют: Sisymbrium altissimum, S. loeselii, S. officinale.

Таблица 7

Ассоциация Atriplici patulae-Tripleurospermetum inodori ass. nov. hoc loco

\begin{tabular}{|c|c|c|c|c|c|c|c|c|c|c|c|}
\hline Номера описаний & 1 & 2 & 3 & 4 & 5 & 6 & 7 & 8 & 9 & 10 & Кп \\
\hline ОПП,\% & 85 & 90 & 90 & 90 & 80 & 80 & 90 & 80 & 90 & 80 & \\
\hline Число видов & 19 & 16 & 17 & 21 & 20 & 17 & 19 & 20 & 16 & 17 & \\
\hline \multicolumn{12}{|c|}{ X. в. acc. Atriplici patulae-Tripleurospermetum indori } \\
\hline Tripleurospermum inodorum & 3 & 4 & 4 & 3 & 2 & 3 & 3 & 3 & 2 & 4 & $\mathrm{~V}$ \\
\hline Atriplex patula & 1 & 2 & 1 & 2 & + & 1 & 1 & 1 & 2 & + & V \\
\hline \multicolumn{12}{|c|}{ Х. в. союза Atriplicion, порядка Sisymbrietalia sophiae } \\
\hline Chenopodium album & 2 & 2 & 3 & 4 & 2 & 2 & 2 & 1 & 2 & 3 & $\mathrm{~V}$ \\
\hline Erigeron canadensis & + & + & . & + & . & + & . & + & . & . & III \\
\hline Artemisia vulgaris & + & + & $\mathrm{r}$ & . & . & + & + & . & . & . & III \\
\hline \multicolumn{12}{|c|}{ Х. в. класса Sisymbrietea } \\
\hline Poa annua & + & + & + & 1 & 1 & . & + & 1 & + & 1 & $\mathrm{~V}$ \\
\hline Capsella bursa-pastoris & + & + & $\cdot$ & $\mathrm{r}$ & $\mathrm{r}$ & . & + & + & . & + & IV \\
\hline Crepis tectorum & + & . & $\mathrm{r}$ & + & + & $\mathrm{r}$ & . & + & . & + & IV \\
\hline Sonchus arvensis & + & . & + & + & + & . & + & $\mathrm{r}$ & r & . & IV \\
\hline Amaranthus retroflexus & $\cdot$ & . & $\cdot$ & $\mathrm{r}$ & + & . & + & $\mathrm{r}$ & . & + & III \\
\hline Convolvulus arvensis & . & . & $\mathrm{r}$ & $\mathrm{r}$ & + & + & . & + & . & $\mathrm{r}$ & III \\
\hline Linaria vulgaris & + & . & $\mathrm{r}$ & + & . & . & $\mathrm{r}$ & . & + & $\mathrm{r}$ & III \\
\hline Malva pusilla & $\cdot$ & + & . & $\mathrm{r}$ & + & $\mathrm{r}$ & . & $\mathrm{r}$ & + & . & III \\
\hline \multicolumn{12}{|c|}{ Х. в. класса Artemisietea vulgaris } \\
\hline Tussilago farfara & + & · & + & $\cdot$ & $\mathrm{r}$ & + & $\mathrm{r}$ & $\mathrm{r}$ & + & . & IV \\
\hline Taraxacum officinale & . & + & . & . & + & $\mathrm{r}$ & + & . & + & + & III \\
\hline Atrium tomentosum & + & . & + & + & . & . & . & $\mathrm{r}$ & . & . & II \\
\hline Elytrigia repens & . & $\mathrm{r}$ & . & . & $\mathrm{r}$ & . & + & + & . & $\mathrm{r}$ & II \\
\hline Melilotus officinalis & . & + & & . & . & . & $\mathrm{r}$ & . & + & . & II \\
\hline \multicolumn{12}{|c|}{ Х. в. класса Molinio-Arrhenatheretea } \\
\hline Poa palustris & + & + & + & + & + & + & + & + & + & . & V \\
\hline Trifolium pratense & + & r & . & + & + & $\mathrm{r}$ & . & . & $\mathrm{r}$ & + & IV \\
\hline Phleum pratense & + & . & + & + & + & . & . & + & + & . & III \\
\hline Poa angustifolia & + & . & $\mathrm{r}$ & + & . & + & . & + & . & . & III \\
\hline Potentilla argentea & . & . & + & . & + & . & + & + & . & . & II \\
\hline \multicolumn{12}{|c|}{ Прочие виды } \\
\hline Rumex acetosella & + & + & $\cdot$ & $\mathrm{r}$ & $\cdot$ & $\mathrm{r}$ & + & $\cdot$ & + & + & IV \\
\hline Trifolium repens & + & + & + & + & . & + & + & + & . & + & IV \\
\hline Veronica serpyllifolia & + & . & + & + & + & . & $\mathrm{r}$ & . & + & $\mathrm{r}$ & III \\
\hline Hieraceum umbellatum & $\cdot$ & $\mathrm{r}$ & · & $\cdot$ & + & + & + & . & + & $\cdot$ & III \\
\hline Polygonum aviculare & . & . & + & $\mathrm{r}$ & $\mathrm{r}$ & + & + & . & . & . & III \\
\hline
\end{tabular}

Примечание. Единично отмечены: Plantago major 10 (+), Trifolium hybridum 10 (+).

Локализация описаний. Брянский $p$-н: 2, 3 - пос. Октябрьский, залежь, после пропашных культур, 20.07.2016; 4 - пос. Добрунь, залежь, 22.07.2017; 9, 10 - пос. Елисеевичи, залежь, 22.08.2018. Г. Брянск: 1 Советский р-н, дачные участки в районе телецентра, бывшее картофельном поле под паром первого года, 6.08.2005. Комаричский p-н: 5, 6 - с. Ольгино, залежь; 7 - с. Аркино, залежь, 20.06.2017; 8 - с. Усожа, залежь, 10.08.2017. Авторы описаний: 1-4 - Булохов А. Д., 5-10 - Ивенкова И. М.

Ассоциация Ivaetum xanthïfoliae Fijałkowski 1967 (табл. 8).

X. в.: Cyclachaena (Iva) xanthiifolia (доминант), Artemisia vulgaris Amaranthus retroflexus. 
Таблица 8

Ассоциация Ivaetum xanthiifoliae субасc. arctietosum tomentosi subass nov. hoc loco

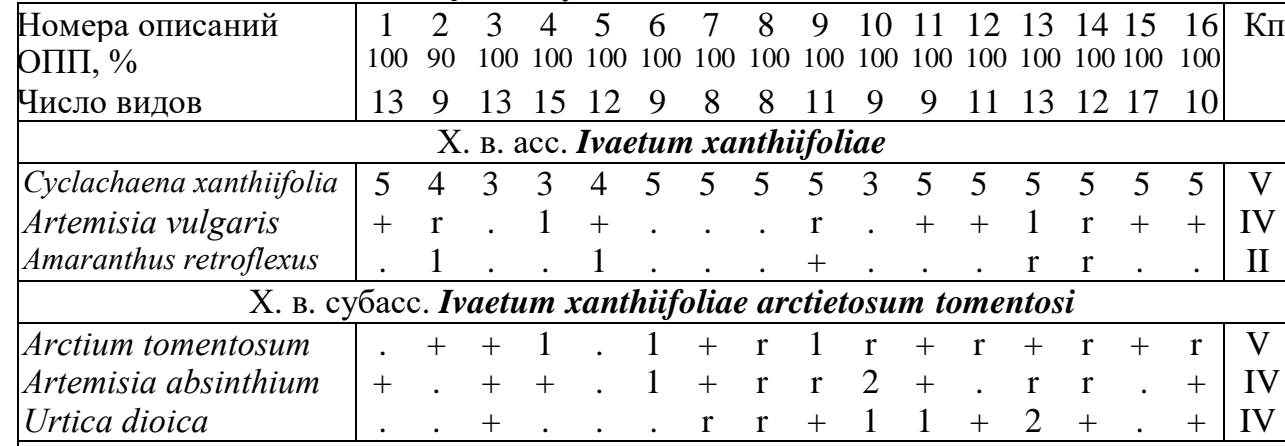

Х. в. союза Atriplicion, порядка Sisymbrietalia sophiae и класса Sisymbrietea

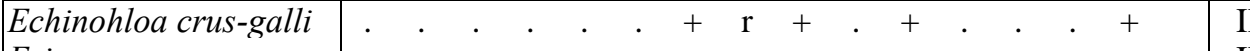

\begin{tabular}{l|llllllllllll} 
Erigeron annuus & $\mathrm{r}$ & $\mathrm{r}$ & $+\mathrm{r}$ &. &. &. &. &. &. & $\mathrm{r}$ & $\mathrm{II}$
\end{tabular}

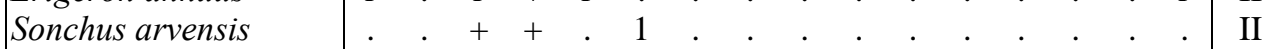

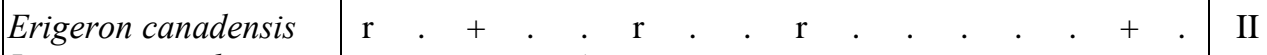



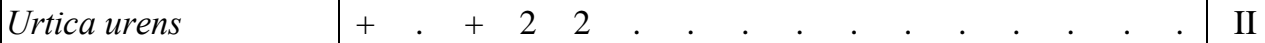

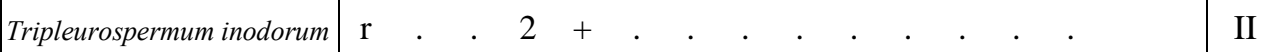



\begin{tabular}{l} 
Х. в. класса Artemisietea vulgaris \\
\hline X
\end{tabular}

\begin{tabular}{|l|llllllllllllllll}
\hline Convolvulus arvensis & + &. & & 1 & 1 & 1 & + & $\mathrm{r}$ & + & + & + & + & + & + & + & $\mathrm{V}$
\end{tabular}

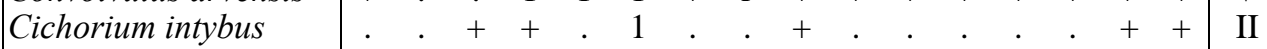

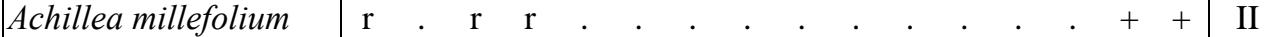

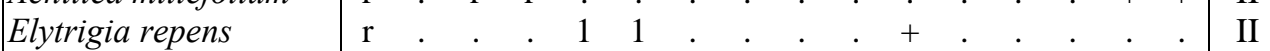

\begin{tabular}{l|llllllllllllllllllll} 
Daucus carota &. &. &. &. &. &. &. &. &. & $\mathrm{r}$ &. & $\mathrm{r}$ & $\mathrm{r}$ & $\mathrm{r}$ &. & . & II
\end{tabular}

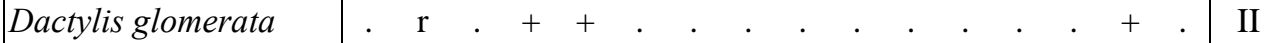



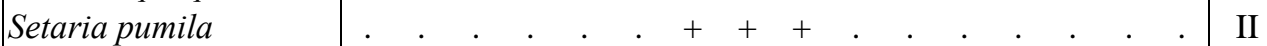

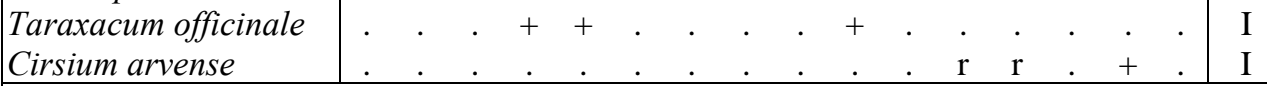

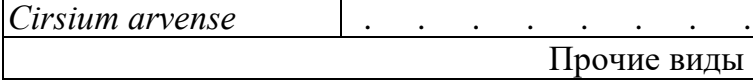

\begin{tabular}{|l|llllllllllllllllll|l} 
Polygonum aviculare & 1 & + &. & 2 &. &. &. &. &. &. &. & 1 & 1 & 1 &. &. & II
\end{tabular}



Примечание. Единично отмечены: Acer negundo 3 (+), 16 (r), Agrostis tenuis 3 (r), 4, 5 (+), Ballota nigra 15 $(+), 16(\mathrm{r})$, Bunias orientalis $1(\mathrm{r}), 6(+)$, Carduus acanthoides $15(\mathrm{r})$, Chamomilla recutita $13(+)$, Chelidonium majus $16(+)$, Chenopodium album $15(+), 16(2)$, Echinocystis lobata $12(+), 33(\mathrm{r})$, Galinsoga parviflora $2(+)$, Galium aparine $14(\mathrm{r})$, Galium mollugo $15(+)$, Geranium sibiricum $16(+)$, Lavatera thuringiaca $15(\mathrm{r})$, Linaria vulgaris $3(+)$, Melilotus officinalis $12(+)$, Poa trivialis $16(+)$, Solidago canadensis $16(\mathrm{r})$, Vicia cracca $15(+)$ Локализация описаний. Выгоничскй р-н: 13 - п. Кокино, окраина фермы КРС, 11.07. 2016. Комаричский $p$ н: 1, 2 - с. Евдокимовка, пустырь, 10.07.2011; 3 - с. Евдокимовка, заброшенный загон фермы КРС, 28.07.2011; 4 - с. Евдокимовка, склон обочины грунтовой дороги, 5.08.2011; 5 - с. Евдокимовка, близи силосных ям, 28.07.2011; 6 - с. Литиж, пустырь, 1.08.2012; 7-9 - с. Угревищи, окраина разрушенной фермы КРС, 8.07.2013; 10 - с. Усожа, окраина фермы КРС, 8.07.2013; 11- п. Пушкино, пустырь, 9.07.2014; 12 - с. Кривцево, окраина фермы КРС, 9.07.2016; 16 - п. Комаричи, пустырь у ж.д., 8.09.2018. Севский p-н: 14 - с. Княгинино, окраина фермы КРС, 9.07.17. Трубчевский р-н: 15 - г. Трубчевск, пойма р. Десна, обочина дороги, 25.07.05. Авторы описаний: 1-9,12 - Ивенкова И. М., 10, 13, 14 - Булохов А. Д, 15, 16 Панасенко Н. Н.

Состав и структура. Облик сообществ в середине и конце лета определяет североамериканский вид-доминант - Cyclachaena 
xanthiifolia. Это высокотравные сообщества высотой до 2 м. В ценофлоре отмечены характерные виды классов Papaveretea rhoeadis и Artemisietea vulgaris. Участие однолетников невелико, возрастает роль многолетников, что свидетельствует о поздней стадии восстановительной сукцессии. Константны и более обильны: Arctium tomentosum, Artemisia absinthium, Convolvulus arvensis, Urtica dioica. Видовое богатство - 9-17 видов на $50 \mathrm{~m}^{2}$.

Местоположение и экология. Сообщества синтаксона распространены в основном в юго-восточной части Брянской области вблизи ферм, по обочинам дорог, пустырям и свалкам. Площади, занимаемые сообществами варьируют от 25 до $3000 \mathrm{~m}^{2}$. Циклахена проникает и в центральные части региона с конца XX века, но является там скорее колонофитом и эфемерофитом, формируя небольшие по площади сообщества (25-100 м $^{2}$ по обочинам дорог и ж.-д. насыпям. Синэкологический оптимум на суховатых $(4,4-4,9)$, в основном, слабощелочных $(6,8-7,3)$, богатых минеральным азотом $(7,1-7,5)$ субстратах.

Вариабильность. В составе ассоциации установлена новая субассоциация.

Субассоциация Ivaetum xanthiifoliae arctietosum tomentosi subass. nov. hoc loco (табл. 8; номенклатурный тип (holotypus) - оп. 12).

X. в.: Arctium tomentosum, Artemisia absinthium, Urtica dioica. Сообщества сформированы многолетними нитрофильными видами, проективное покрытие однолетников не более 20-25\%. Синтаксон представляет продвинутую стадию восстановительной сукцессии.

Типичные местообитания: обочины дорог, загоны, заброшенные и действующие животноводческие фермы, пустыри вблизи ферм.

Экономическое значение и биологическая опасность. Обладая высокой семенной продуктивностью (в среднем 6,5 тыс. семян с одной особи) Cyclachaena xanthiifolia быстро распространяется, проявляет свойства трансформера и подавляет развитие других видов в сообществе (Абрамова, 2003, 2015). С практической точки зрения Cyclachaena xanthiifolia опасный аллергенный сорняк. В настоящее время этот вид приурочен в основном к рудеральным местообитаниям и случаи его внедрения в естественные сообщества не отмечены, но в будущем, возможно, более широкое распространение вида. Для ограничения распространения циклахены данные сообщества необходимо регулярно выкашивать.

Анализ синтаксономического положения ассоциации. Сообщества с доминированием Cyclachaena xanthiifolia относят к ассоциациям Ivaetum xanthiifoliae Fijalk. 1967, Sisymbrio-Ivaetum xanthiifoliae Passarge 1996 и к дериватным сообществам (Абрамова, 2003, 2015; Поцепай, 2008; Панасенко и др., 2013). 
В сообществах синтаксона на территории Брянской области отсутствуют многие характерные виды, установленные для сообществ Ivaetum xanthiifoliae в Чехии (Vegetace..., 2009): Amaranthus albus, Atriplex tatarica, Bromus sterilis, B. tectorum, Carduus acanthoides, Conium maculatum, Datura stramonium, Echinops sphaerocephalus, Erysimum cheiranthoides, Galinsoga parviflora, Hordeum murinum, Lolium perenne, Sisymbrium altissimum, S. loeselii, S. officinale, Solanum nigrum. Для диагностики ассоциации достаточно использовать виддоминант Cyclachaena xanthiifolia.

Заключение. Описанные в работе сообщества сегетальной растительности Южного Нечерноземья представляют ранние стадии востановительной сукцессии на залежах и существуют 1-2 года. Ассоциации Apero spicae-venti-Elytrigetum repentis, Convolvulo arvensi-Erigeronetum canadensis, Chenopodio albi-Setarietum pumilae, Setario pumilae-Galinsogetum parviflorae широко распространены в регионе и развиваются на дерново-подзолистых и серых лесных почвах. Преимущественно в центральных и юго-восточных районах региона на серых лесных почвах встречаются сообщества ассоциаций Artemisio vulgaris-Tripleurospermetum inodori и Atriplici patulaeTripleurospermetum inodori.

Рудеральные сообщества ассоциации Sisymbrietum loeselii и сообщетва Sisymbrium volgense распространяются преищественно по железнодорожным местообитаниям и распространены спорадически. Сообщества ассоциации Ivaetum xanthiifoliae определяют облик антропогенных местообитаний в юго-восточной части региона.

\section{Список литературы}

Абрамова Л.M. 2003. Cyclachaena xanthiifolia в южных районах Предуралья (Башкортостан) // Бот. журн. Т. 88. № 4. С. 67-76.

Абрамова Л.М. 2015. Классификация сообществ с инвазионными видами на Южном Урале. II. Сообщества с участием видов из родов Cyclachaena Fresen. и Xanthium L. // Растительность России. № 27. С. 24-39.

Арепьева Л.А. 2015. Синантропная растительность города Курска. Курск: Курский государственный университет. 203 с.

Булохов А.Д. 2017. Термофильные сообщества железнодорожных насыпей в Южном Нечерноземье России (в пределах Брянской области) // Бюллетень Брянского отделения Русского ботанического общества. № 4 (12). С. 16-28.

Булохов А.Д., Семенищенков Ю.А. 2006. Компьютерная программа INDICATOR и методические указания по ее использованию для экологической оценки местообитаний и анализа флористического разнообразия растительных сообществ. Брянск: РИО БГУ. 30 с. 
Булохов А.Д., Харин А.В. 2008. Растительный покров Брянска и его пригородной зоны (синтаксономия и мониторинг). Брянск: РИО БГУ. 310 с.

Булохов А.Д., Ивенкова И.М. 2013. Фитоценотическая активность видов из рода Erigeron L. (Asteraceae) и рода Oenothera L. (Onagraceae) в Брянской области // Бюллетень Брянского отделения Русского ботанического общества. №2 (2). С. 47-54.

Булохов А.Д., Ивенкова И.М., Панасенко Н.Н., Семенищенков Ю.А, Дайнеко Н.М. 2016. Синантропная растительность Сожско-Деснинского междуречья // Известия Самарского научного центра РАН. т. 18. №5-2. С. 198-205.

Панасенко Н.Н., Ивенкова Е.М., Елисеенко Е.П. Сообщества неофитов в Брянской области // Российский Журнал Биологических Инвазий. 2012. № 2. C. $105-114$.

Панасенко Н.Н., Анищенко Л.Н., Поцепай Ю.Г. 2013. Новые сведения о сообществах инвазионных видов в Брянской области // Бюл. МОИП. Отд. биол. Т. 118. № 1. С. 73-80.

Поцелай Ю.Г. Синантропная растительность и её использование для фитомелиорации селитебных территорий: на примере Брянской области: Дис. канд. биол. наук. Брянск, 2008. 322 с.

Braun-Blanquet J. 1964. Pflanzensociologie. Grundzuge der Vegetationskunde. 3 Aufl. Wien; New York. 865 S.

Ellenberg H., Weber H. E., Düll R., Wirth V., Werner W., Paulißen D. 1992. Zeigerwerte von Pflanzen in Mitteleuropa // Scripta Geobotanica. V. 18. 2. Aufl. $258 \mathrm{~s}$.

Mucina L., Bültmann H., Dierßen K., Theurillat J.-P., Raus T., Carni A., Sumberova K., Willner W., Dengler J., Gavilan Garcia R., Chytry M., Häjek M., Di Pietro R., Iakushenko D., Pallas J, Daniels F. J.A., Bergmeier E., Santos Guerra A., Ermakov N., Valachovic M., Schaminée J. H. J., Lysenko T., Didukh Y. P., Pignatti S., Rodwell J. S., Capelo J, Weber H. E., Solomeshch A., Dimopoulos P., Aguiar C., Hennekens S. M., Tichy L. 2016. Vegetation of Europe: hierarchical floristic classification system of vascular plant, bryophyte, lichen, and algal communities // Applied Vegetation Science. Vol. 19 (Suppl. 1). P. 3-264.

Vegetace Ceské republiky. 2009. 2. Ruderalrn, plevelova, skalni a sut'ova vegetace/M. Chytry (ed.). Praha. $520 \mathrm{~s}$.

Weber H.E., Moravec, J., Theurillat J.-P. 2000. International code of Phytosociological Nomenclature. 3rd edition. // J. Veg. Sci. V.11. № 5. P. 739768.

\title{
COMMUNITIES OF THE CLASS PAPAVERETEA RHOEADIS S. BRULLO ET AL. 2001 AND SISYMBRIETEA GUTTE ET HILBIG 1975 IN THE SOUTHERN NECHERNOZEMIE REGION OF RUSSIA
}

\author{
A.D. Bulokhov, I.M. Ivenkova, N.N. Panasenko \\ Petrovsky Bryansk State University, Bryansk
}

The results of classification of anthropogenous vegetation of the Southern Nechernozemie Region of Russia, representing the classes Papaveretea rhoeadis and Sisymbrietea, are presented. 5 new associations of segetal and 
ruderal vegetation have been established: Apero spico-venti-Elytrigetum repentis, Chenopodio albi-Setarietum pumilae, Convolvulo arvensiErigerntetum canadensis, Artemisio vulgaris-Tripleurospermetum indori, Atriplici patulae-Tripleurospermetum indori. Communities of associations represent quickly passing stages of progressive succession. Associations are included in the structure of alliances: Galeopsion bifidae, Oxalidion europaeae, Scleranthion annui, Atriplicion.

Keywords: classification, Braun-Blanquet approach, anthropogenic vegetation, segetal and ruderal communities, Papaveretea rhoeadis, Sisymbrietea, Bryansk region.

Об авторах:

БУЛОХОВ Алексей Данилович - доктор биологических наук, профессор, заведующий кафедрой биологии, ФГБОУ ВО «Брянский государственный университет имени академика И.Г. Петровского», 241036, Брянск, ул. Бежицкая, 14, e-mail: kafbot2002@ mail.ru.

ИВЕНКОВА Ирина Михайловна - аспирант кафедры биологии, ФГБОУ ВО «Брянский государственный университет имени академика И.Г. Петровского», 241036, Брянск, ул. Бежицкая, 14, еmail: irina.ivenckova@yandex.ru.

ПАНАСЕНКО Николай Николаевич - кандидат биологических наук, доцент, доцент кафедры биологии, ФГБОУ ВО «Брянский государственный университет имени академика И. Г. Петровского», 241036, г. Брянск, ул. Бежицкая, 14, e-mail: panasenkobot@ yandex.ru.

Булохов А.Д. Сообщества классов Papaveretea rhoeadis S. Brullo et al. 2001 и Sysymbrietea Gutte et Hilbig 1975 в южном Нечерноземье России / А.Д. Булохов, И.М. Ивенкова, Н.Н. Панасенко // Вестн. ТвГУ. Сер. Биология и экология. 2019. № 2(54). C. 103-122. 